\title{
Prediction of soil desiccation and yield loss adopting new plant physiological thresholds in apple forests on the Chinese Loess Plateau
}

\author{
Fuxing Guo ${ }^{1}$, Haowei $\mathrm{Sun}^{2}$, Fuyong $\mathrm{Wu}^{3}$, and Yanping Wang ${ }^{1}$ \\ ${ }^{1}$ Northwest Agriculture and Forestry University College of Resources and Environment \\ ${ }^{2}$ Northwest A\&F University \\ ${ }^{3}$ Northwest Agriculture and Forestry University
}

September 24, 2021

\begin{abstract}
Plant physiological thresholds, based on the response of plant physiological parameters to soil available water, were proposed to optimize soil drought and desiccation studies. However, further research is lacked to explore the discrepancy between plant physiological thresholds and traditional threshold, stable field capacity (SFC), in prolong drought modelling. This discrepancy may misjudge the occurrence and severity of dry soil layer (DSL) and bring uncertainty to vegetation selection and planting years estimation. In this study, Environment Policy Integrated Climate (EPIC) model was used to predict soil water dynamics and drought yield loss (YL) in apple main production zone on the Chinese Loess Plateau from 2021 to 2080 under four General Circulation Models (GCMs). Subsequently, plant physiological thresholds were determined with leaf net photosynthetic (TPN) and transpiration rate (TTR) and compared with SFC in long-term DSL prediction. The present results showed that TPN and TTR significantly slowed down the formation of DSL and enhanced the correlation between DSL and YL. Forming serious DSL (Quantitative Index, QI > 0.5) has slowed from 20 to 30 years, and R2 of YL and QI increase from 0.265 to 0.528 (QIPN) and 0.409 (QITR). Moreover, future climate change accumulatively reduced 9.95-14.18\% of the YL. These results indicated that traditional method overestimated the environmental contradiction between economic benefits and eco-hydrology of apple forests, which could bring unreliable messages to policymaker to restrict further development of apple industries. This study was emphasized that evaluating DSL based on plant physiological threshold reflected better plant growth and water stress, which contributed to further study the sustainable development of fragile ecosystem.
\end{abstract}

\section{Hosted file}

MANU.docx available at https://authorea.com/users/434969/articles/538314-prediction-of-soildesiccation-and-yield-loss-adopting-new-plant-physiological-thresholds-in-apple-forestson-the-chinese-loess-plateau 

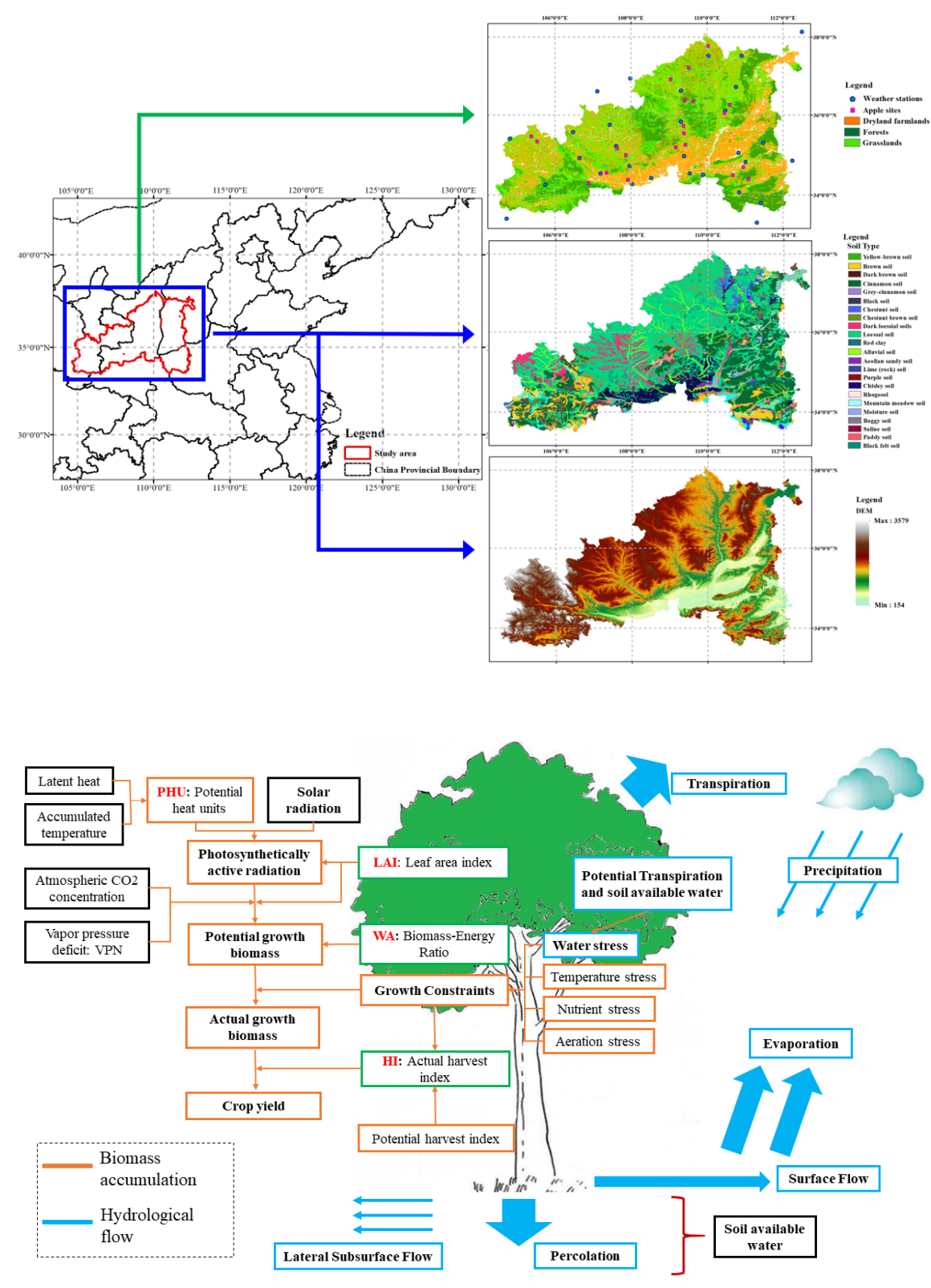


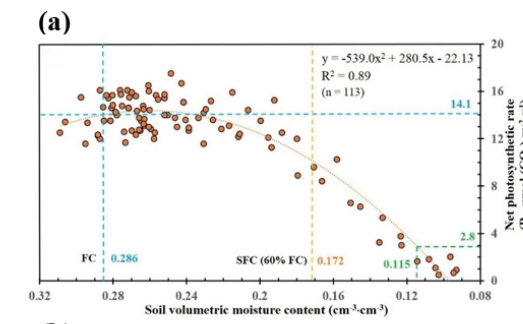

(b)
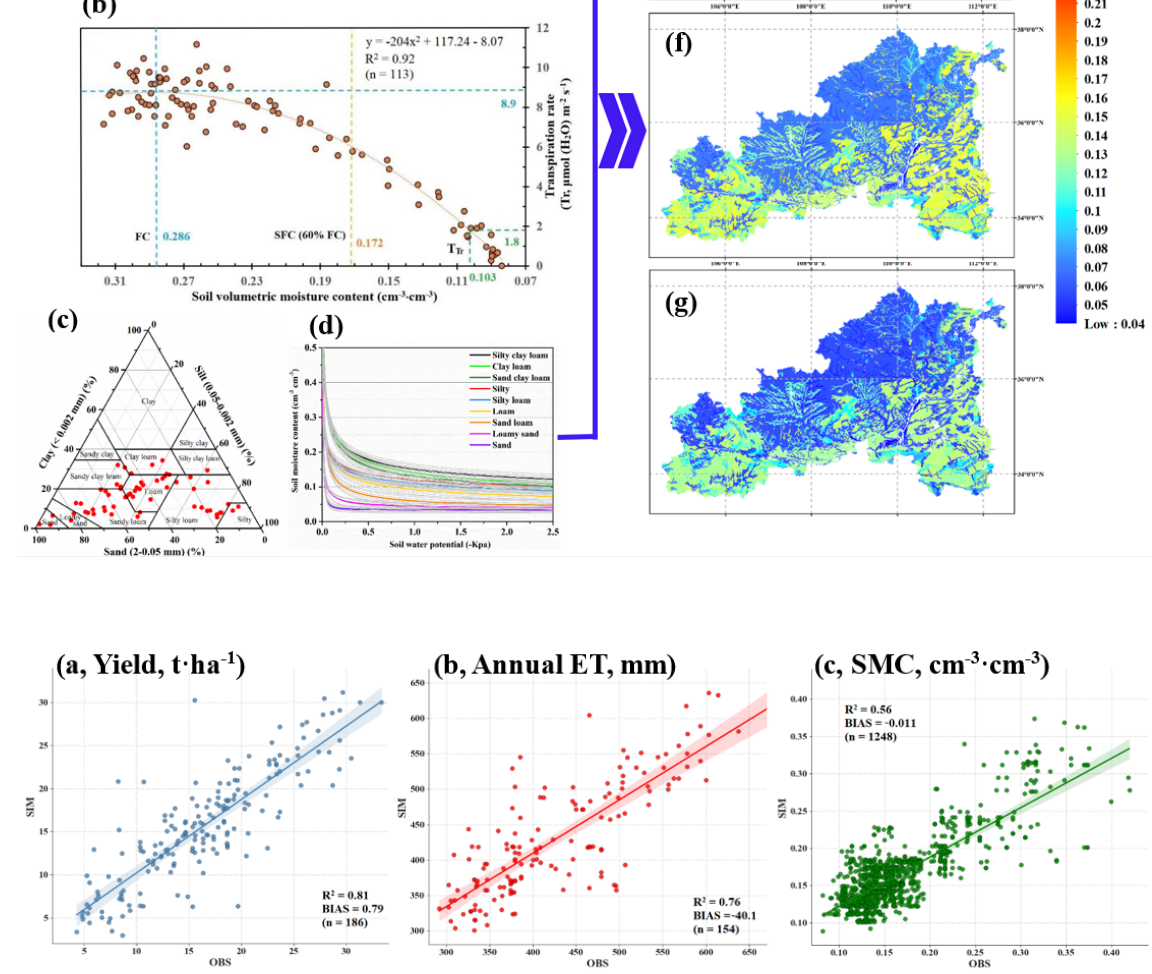

(c, $\mathrm{SMC}, \mathrm{cm}^{-3} \cdot \mathrm{cm}^{-3}$ )
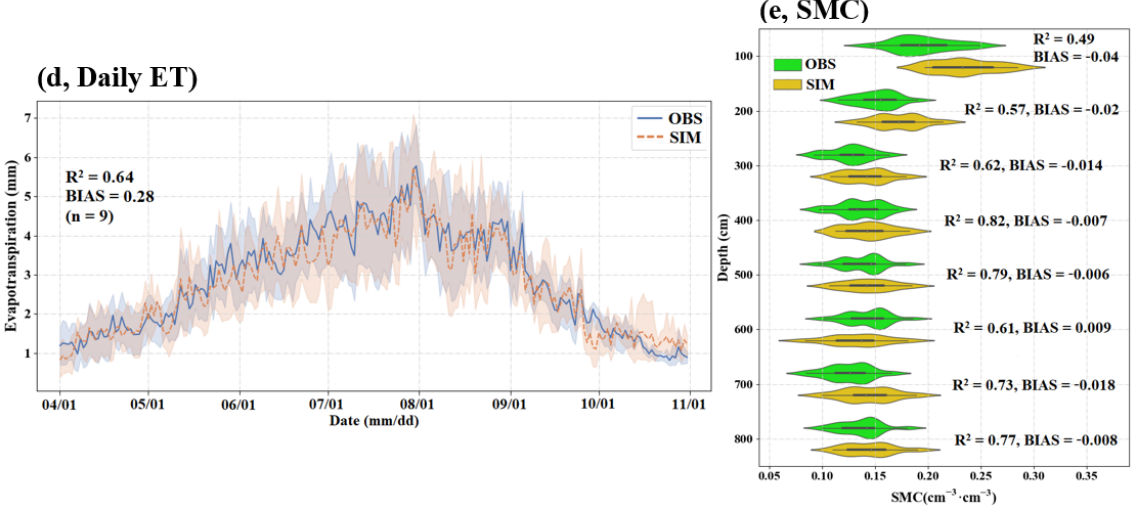

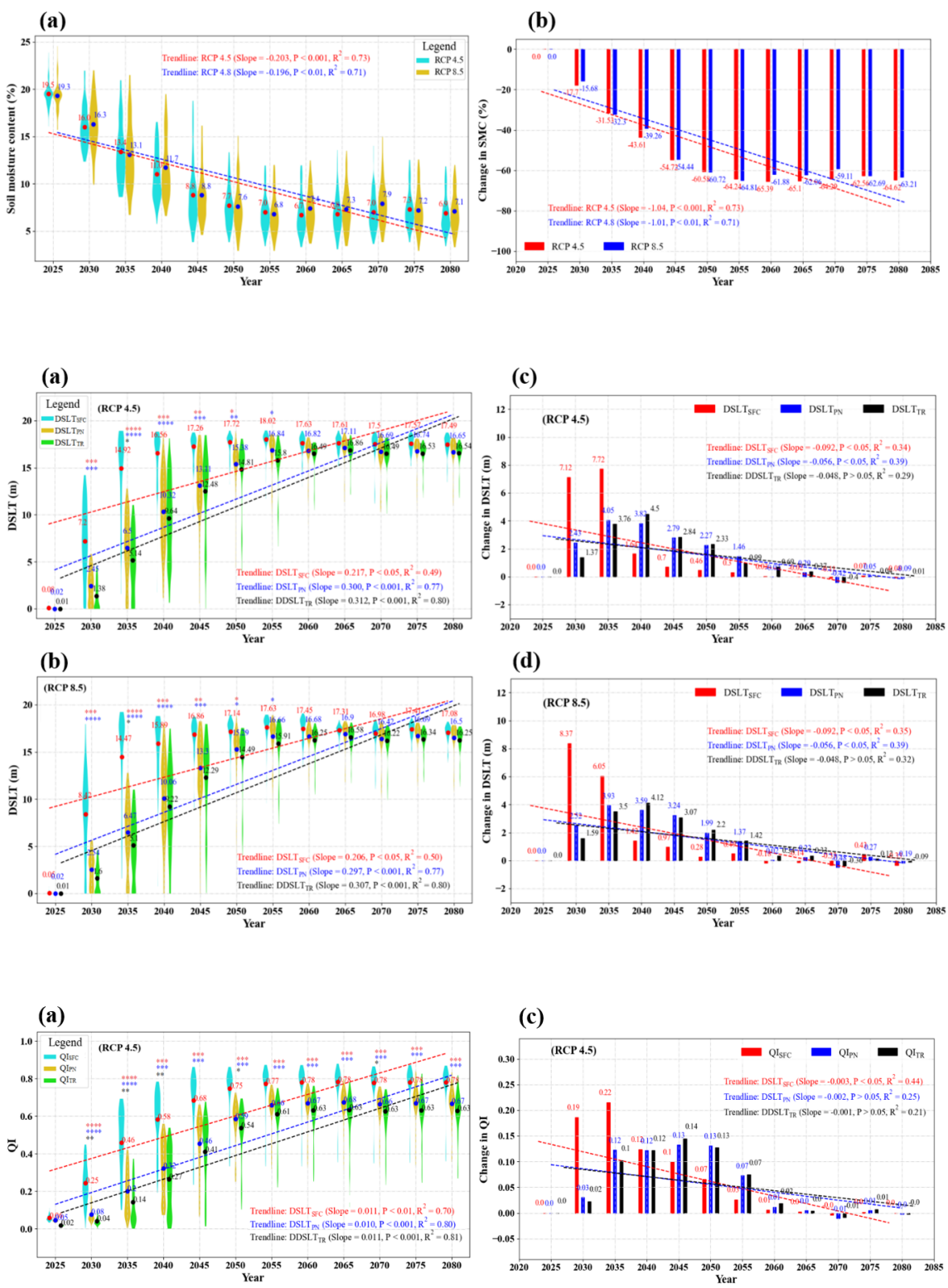

(b)

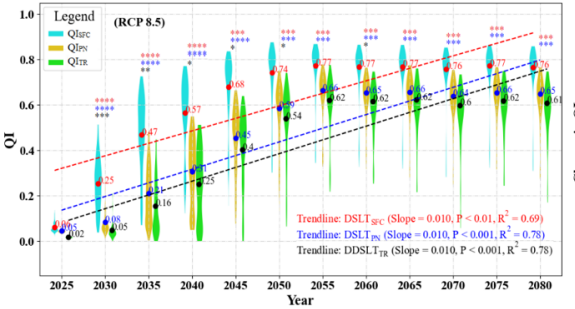

(d)

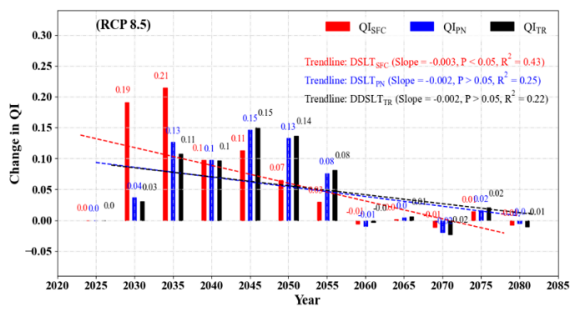




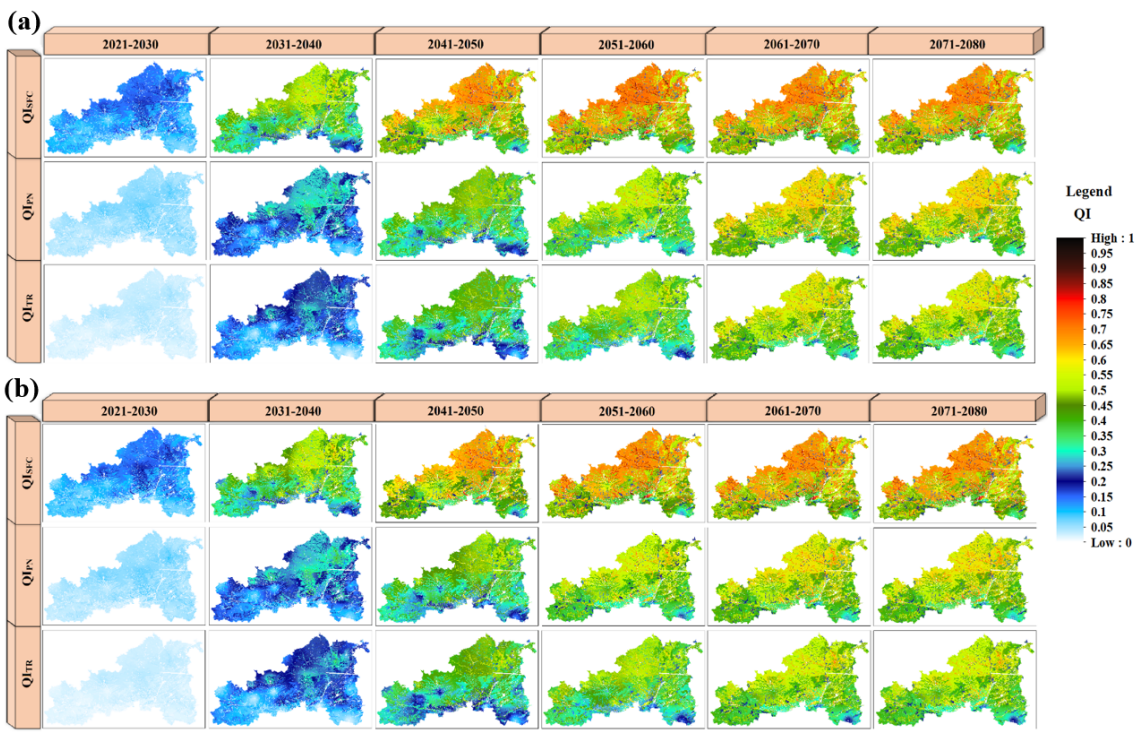

(a)

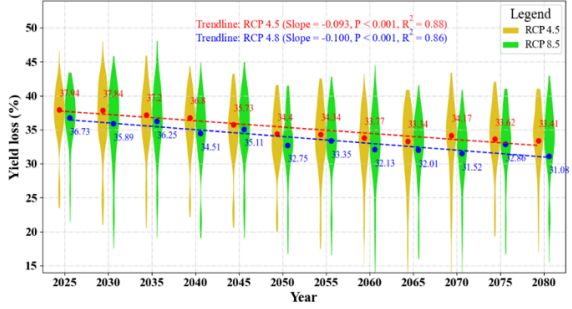

(b)

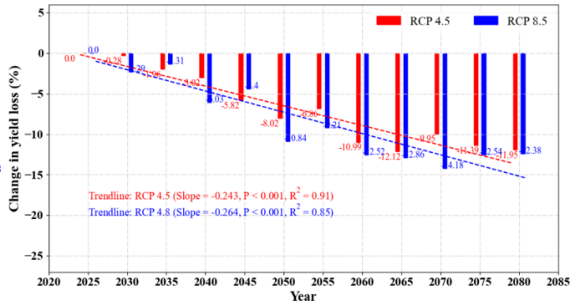

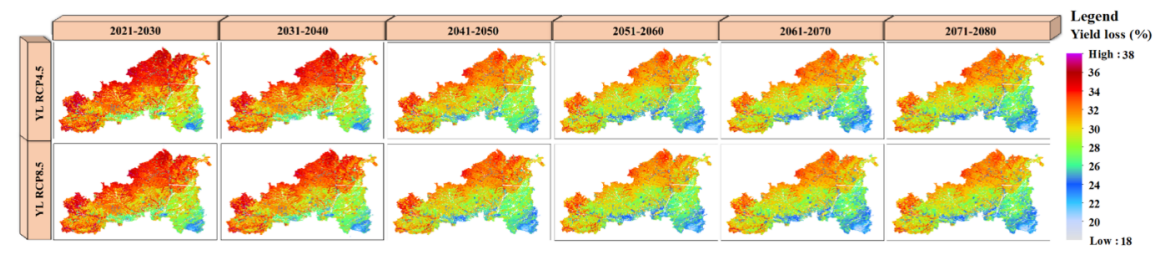

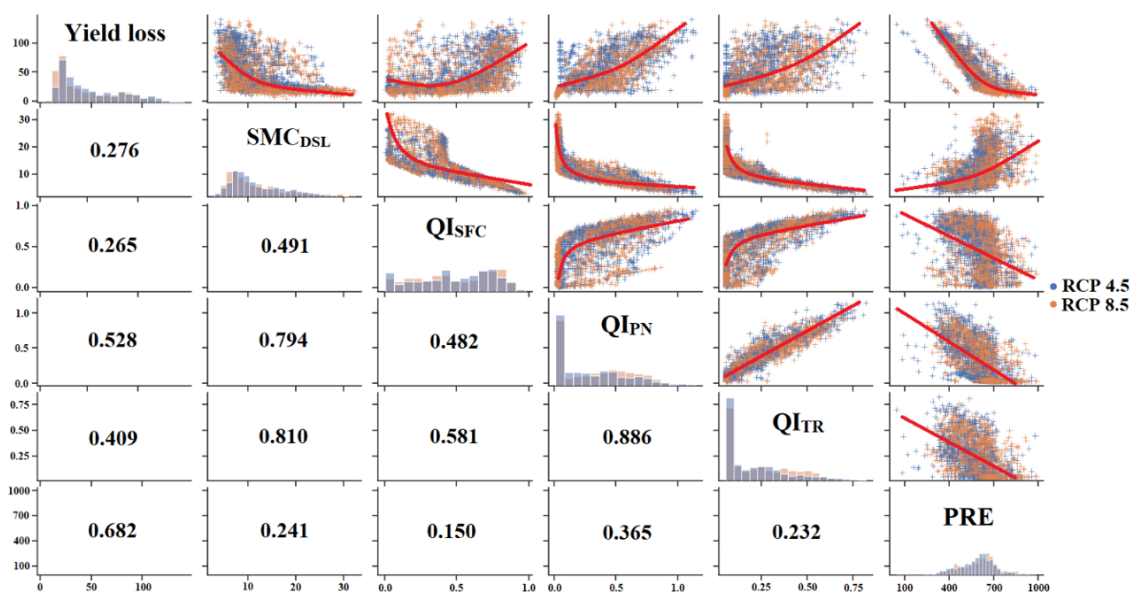

